\title{
Ensuring patient adherence to clean intermittent self-catheterization
}

This article was published in the following Dove Press journal:

Patient Preference and Adherence

12 February 2014

Number of times this article has been viewed

Jai H Seth

Collette Haslam

Jalesh N Panicker

Department of Uro-Neurology, University College London Institute of Neurology and the National Hospital for Neurology and Neurosurgery, London, UK

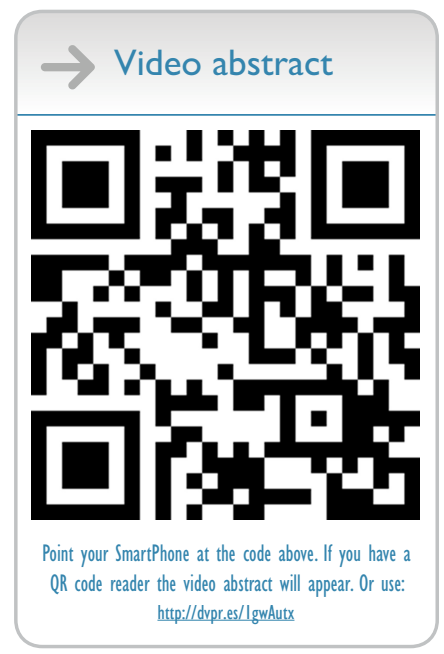

Correspondence: Jai H Seth

Department of Uro-Neurology,

University College of London, Institute of Neurology and the National Hospital for Neurology and Neurosurgery, London WCIN 3BG, UK

Email seth.jai@gmail.com
Abstract: Patient performance of clean intermittent self-catheterization is a crucial component of the management of incomplete bladder emptying, which can arise from a variety of conditions. This allows patients to have more control over their bladder emptying, and avoids the inconveniences that come with an indwelling urethral catheter. There are, however, barriers that patients face when performing this task which may ultimately limit adherence. In this article, these barriers are discussed in more detail with potential solutions to counter them.

Keywords: clean intermittent self-catheterization, catheters, barriers, compliance, adherence

\section{Introduction}

Voiding difficulties are a common manifestation of lower urinary tract dysfunction. Patients may present with obstructed voiding and incomplete bladder emptying or present in complete urinary retention. Not only may this exacerbate storage symptoms, ie, urinary urgency, frequency, nocturia, and incontinence, it may also predispose to a spectrum of complications including recurrent urinary tract infections (UTIs), bladder stones, upper urinary tract changes, and even renal impairment. The management of urinary retention is limited to physical means of bladder drainage using a catheter. The introduction of intermittent catheterization was a significant advancement. Sterile intermittent catheterization was initially described in 1966 by Guttmann and Frankel for the management of patients with neurogenic bladder dysfunction consequent to spinal cord injury $(\mathrm{SCI})^{1}$ and was an elaborate procedure involving a "catheter team" using sterile gloves and forceps to avoid infection. Subsequently, the concept of clean intermittent catheterization was introduced by Lapides et $\mathrm{al}^{2}{ }^{2}$ and studies have shown this to be noninferior to sterile catheterization. ${ }^{3}$

\section{Clean intermittent self-catheterization (CISC)}

CISC is now considered the gold standard for the management of urinary retention. The International Continence Society defines CISC as use of a clean technique to drain the bladder with subsequent removal of the catheter, which is performed by the patient himself/herself. ${ }^{2,4}$ It implies that the technique is clean and that it involves ordinary washing techniques, and the use of disposable or cleansed reusable catheters.

Incomplete bladder emptying and urinary retention are common in patients with lower urinary tract dysfunction consequent to neurological disease and are most often due to detrusor underactivity or detrusor sphincter dyssynergia. Pharmacological interventions are usually ineffective and therefore CISC plays a central role in management. ${ }^{5,6}$ 
Moreover, urinary retention is an important adverse event with certain treatments for the overactive bladder. For example, onabotulinumtoxinA has recently been licensed for use in the management of neurogenic detrusor overactivity in several countries, and urinary retention is a side effect. ${ }^{7,8}$ Patients with SCI may sometimes undergo reconstructive urological surgery ${ }^{9}$ such as bladder augmentation, and either through the urethra or an additional Mitrofanoff umbilical appendicovesicostomy, the patient or caregiver empties the bladder intermittently using a catheter. Therefore, there is an important role for intermittent catheterization in treatment pathways.

Intermittent catheterization has been shown to improve quality of life by providing better symptom management, reduction in the frequency of voids, which is especially beneficial at night, and improved sleep thereby reducing daytime fatigue. ${ }^{10,11}$ Emptying the bladder reduces the incidence of urinary leakage and may result in fewer UTIs. The increased confidence of managing bladder symptoms gives the patient greater freedom to participate in daily and social activities that may have otherwise been difficult. ${ }^{10}$ Kessler et al evaluated patients performing CISC over a 5 -year period and reported that $80 \%$ of patients found CISC to be easy and not interfering with activities of daily living. ${ }^{11}$ In short, CISC is a relatively simple and quick procedure which allows patients to independently manage bladder emptying in the community, reducing bladder symptoms, and also safe-guarding renal functions.

\section{Compliance to CISC}

In spite of the many attributes of CISC, compliance rates often dwindle during long-term follow-up. A retrospective evaluation of patients with SCI showed that the vast majority (up to $92 \%$ ) continued to perform CISC in the intermediate term. ${ }^{12}$ The $8 \%$ of patients who discontinued attributed this to recurrent UTIs or poor satisfaction. Of the patients performing CISC, 72\% did not need assistance, $23 \%$ needed assistance with positioning or managing clothing, and $4 \%$ were completely dependent on others to assist with the technique. ${ }^{12}$ Chai et al examined adherence to CISC in a cohort of patients with SCI, and showed that after a mean of 5.9 years, only $71 \%$ were compliant with this method of bladder emptying. ${ }^{13}$ A prospective cohort of 60 patients performing CISC, of whom 30 had neurological disease, were followed up at regular intervals following CISC training for 1 year. ${ }^{14}$ The adherence rate was only $58 \%$ at 1 year; however, it was shown that quality of life measures on the psychological and social relationships domains of the World Health Organization Quality of Life (WHOQoL) ${ }^{14}$ brief tool were significantly higher in patients who had adhered to CISC. Interestingly the patient's educational background, marriage status, detrusor leak point pressure, bladder capacity, and number of leakage episodes did not affect the adherence rate. It appeared that most of the adherent patients were women, patients with a neurological disease, and those under the age of 40 years. ${ }^{14}$ Patients were also asked about their regime for performing CISC and $77 \%$ reported a schedule that was consistent to the one suggested by their clinician, $46 \%$ were catheterizing to their own schedule, and $20 \%$ catheterized in response to a feeling of bladder fullness. Other retrospective reviews report CISC compliance rates ranging from $34 \%$ to $81 \% .{ }^{15,16}$ It is essential that units involved in the teaching of CISC should follow patients, audit adherence levels, and document reasons for noncompliance to obtain a realistic picture of the difficulties with CISC.

Very few studies have explored the factors responsible for nonadherence to CISC. Both internal and external factors may pose as barriers to successful CISC. Internal factors broadly consist of patient related factors that include physical or psychological barriers. Practical barriers refer to the physical factors that hinder catheterization and psychological barriers refer to the psychosocial and cultural aspects that may restrict its use. ${ }^{17}$ External factors involve the quality of the teaching of CISC, supervision, follow-up, and catheter availability in the community. A summary of these barriers and approaches to improving adherence are listed in Table 1.

\section{Internal factors affecting adherence to performing CISC}

A survey of 44 patients performing CISC for a variety of indications revealed that most patients $(73 \%)$ reported at least one practical barrier to CISC. ${ }^{18}$ These patients were residing within the community, and had been using CISC for at least 2 months, with a mean use of 60 months. The most commonly reported barrier was lack of access to a public toilet (34\%). Other barriers included difficulty positioning to insert the catheter (25\%) and problems with dexterity in $21 \%$ of patients, especially in patients with multiple sclerosis (MS). Eighteen percent of patients reported that cost of supplies was also a barrier. Only half of the patients claimed to be completely satisfied with CISC, $40.9 \%$ were somewhat satisfied, and $9.1 \%$ were not satisfied. The commonly reported 
Table I Barriers to clean intermittent catheterization and proposed suggestions to improve adherence

\begin{tabular}{ll}
\hline Barriers & Suggestions for improving adherence \\
\hline Internal factors (patient related) & - Face to face instructions with a nurse with experience in teaching CISC \\
Physical disabilities & - Choosing the appropriate catheter \\
- Positioning & - Use of catheter appliances to help locate the urethra \\
- Dexterity & $\circ$ Thigh abductors \\
- Visual impairment & $\circ$ Mirrors \\
- Anatomical & $\circ$ Labia spreaders \\
- Cognition & - Seek advice from a urologist regarding surgical management for anatomical \\
Psychological factors & obstructions \\
- Misconceptions and anxiety & - Use of visual aids, leaflets, videos \\
- Embarrassment and poor confidence & \\
- Stigma & \\
- Fears & - Providing adequate time for teaching \\
External factors & - Ensuring regular follow-up when required \\
- Access to public toilets & - Engaging with carer/partner when appropriate \\
- Inadequate facilities in public toilets & - Standardized training of continence nurses \\
- Availability of appropriate catheters and assistance appliances & - Adequate budgetary provision for catheters and appliances \\
- Quality of teaching and the training environment & - Efficient catheter delivery system in the community \\
- Community follow-up access to help or advice & - Optimizing communication between primary and secondary/tertiary care \\
- Availability of experienced nurse specialists & - Engaging with district nurses for optimizing support in the community \\
& - Role for industry in improving community support \\
& - Access to locked disabled toilets (eg, National Key Scheme) \\
\hline
\end{tabular}

Abbreviation: CISC, clean intermittent self-catheterization.

internal factors that limit adherence are discussed in more detail below.

\section{Physical disabilities Positioning}

Positioning in preparation for performing CISC involves a number of key skills: organizational skills (preparation of materials), broad motor skills (when and how to sit and stand), fine motor skills (hand dexterity), and sensory input (perception and interpretation of sensory input). Patients with neurological deficits affecting any of these functions face difficulties in performing CISC. However, patients without neurological disease may also report difficulties in positioning. Factors such as mobility, balance, dexterity, and central obesity may interfere with positioning for introducing the catheter into the urethra. Certain appliances are available to facilitate the ease of self-catheterization which can help tackle these practical obstacles and are discussed further below.

\section{Dexterity}

Problems with dexterity are common following neurological disease and result from impaired motor functions as well as sensations from the hand. Moreover, musculoskeletal disorders such as osteoarthritis and rheumatoid arthritis may also impact a patient's ability to perform catheterization. Manual dexterity should be considered when assessing a patient for CISC. Recently, a tool has been validated for use in patients with neurological disease secondary to SCI and MS, called the Pencil and Paper test, ${ }^{19}$ which employs a series of simple tasks using a pencil and paper. This test mimics the ability to open the packaging and handle a catheter, as well as cognitive strategies required to accomplish this. ${ }^{19}$

\section{Visual impairment}

Visual impairment can pose a barrier in some individuals. In partially sighted individuals, teaching by an experienced practitioner and ongoing support thereafter may help to address this barrier. The catheterization technique may be modified for individual needs, and could involve providing greater awareness about urogenital anatomy without the use of aids such as a mirror.

\section{Anatomical}

Anatomical barriers that can potentially reduce the success and ease of CISC are obstructions to the outflow of urine from the bladder and are usually either due to an enlarged prostate or to urethral stricture disease. These conditions 
would require further investigation by an urologist who may consider surgical options to alleviate any significant obstruction.

\section{Cognition}

Comprehension, attention, memory, and motor planning are the relevant cognitive domains that are required to perform self-catheterization, and therefore, the assessment of the patient should include a brief assessment of these domains. For CISC to be successful, the individual should be aware of the need to catheterize and respond accordingly. Memory of the technique is also paramount, which includes the correct sequence of steps for the procedure, as well as measures to ensure hygiene. In our experience, the nurse teaching CISC should be aware of the neurological condition and associated deficits of the patient. The challenges are far greater when the patient has a progressive condition such as Alzheimer's disease, as compared to a static condition such as traumatic brain injury. Vahter et al demonstrated that in a group of patients with MS, cognitive decline did not influence the ability to learn CISC. However, the time spent teaching patients CISC has a significant impact on adherence. ${ }^{20}$ Therefore, planned sessions allowing at least 1 hour are recommended, especially for the initial instruction. It is likely that CISC is possible in individuals with mild and even moderate cognitive deficits; however, success hinges upon spending adequate time and follow-up either over the telephone or face to face.

\section{Psychological barriers to CISC}

A prospective study which evaluated patients with SCI who went on to learn CISC observed that the teaching and service provision during acute rehabilitation was excellent, with acceptance of and gaining of competence of CISC. However, after discharge from hospital, the follow-up in the community was poor, and patients were often not supported. ${ }^{21}$ Jaquet et al studied the experiences of eight patients and observed that the news of potentially having to carry out CISC lifelong could result in a crisis reaction which adversely affected performance. $^{22}$

\section{Misconceptions and anxiety}

A study by van Achterberg et al assessed two aspects of CISC adherence. The first aspect was the initial mastery of the technique and short-term adherence, whilst the second part examined long-term adherence. ${ }^{23}$ There were several determinants that influenced mastery of the technique. These included the patient's knowledge of the underlying disease, as well as anatomy of the lower urinary tract, which if inadequate, could hinder the learning process. Some women, even at the age of 65 years, mentioned that they had never inspected their own vagina and would struggle to find the urethra, and the need to discover a new region of the body contributed to anxiety about learning the procedure. Patients also reported misconceptions about CISC, and held assumptions that CISC would invariably be painful, lead to infections, worsen incontinence, or result in a "lazy bladder." Another factor was the perceived complexity of the task, and patients were worried about finding the procedure too overwhelming and would have difficulties memorizing the task. $^{23}$ It was also observed that a single visit led to anxiety, and patients often preferred to attend an initial visit to understand the procedure, and then return for a second visit to actually learn the technique.

The perception that CISC is a time consuming procedure has been cited as a barrier to CISC. ${ }^{18}$ This perception usually arises during the initial teaching. However, with practice and increasing confidence, this can be greatly reduced and the experienced patient may not require much more time than that required to pass urine naturally.

\section{Embarrassment and poor confidence}

Younger patients have felt that the need to perform CISC added to their "sickness role," affecting motivation and thereby influencing adherence, especially if they already had other disabilities from their underlying illness. ${ }^{23}$ They also felt that this had an impact on forming relationships, affecting intimacy and sexuality, and they sometimes resorted to skipping CISC when they expected to be engaged in sexual activity. Patients often have to learn CISC when they are still becoming accustomed to their illness and the disabilities it brings. There are many psychological adjustments to be made when a neurological diagnosis is made which have an impact on health, work, and relationships. They often felt it was too early in the journey to accept CISC. ${ }^{23}$ Given more time, they would have mastered the skills and accepted CISC more easily. The need to perform CISC may also result in embarrassment, strain on family relationships, and impact confidence ${ }^{24,25}$ which are important when assessing a patient.

\section{Stigma}

Even today, a stigma exists in society towards urinary problems in general, and this is a cause for reluctance to catheterize. Some patients have reported a feeling of shame when having to perform CISC. The importance given to secrecy and discretion results in some patients avoiding CISC in public toilets or at other people's homes. Negative feelings 
and experiences from the past may lead to low motivation. Patients may view CISC as a task they are compelled to perform, rather than a technique that brings with it choice and freedom about managing urinary troubles.

\section{Fears}

Factors that affect long-term adherence include fear about the technique. ${ }^{23}$ Patients may be afraid of entering their body with a catheter, causing infection, pain, or irreversibly injuring the urinary tract when inserting the catheter. These can impact the learning process during the teaching session. Linked with this is the confidence about maintaining hygiene. Some patients fear that performing CISC would be a step towards eventually having to be catheterized by others, thereby resulting in a loss of independence. These are all valid concerns and patients should be reassured of the safety and reminded of the reasons for performing the procedure and how it can provide independence.

\section{External factors affecting adherence to performing CISC}

Guidance from the UK Department of Health Good Practice in Continence Services and the National Service Framework for Long Term Conditions suggest that patients with bladder problems should have access to an integrated continence service. ${ }^{26,27}$ The type of training, support, and follow-up given to patients taking up CISC is fundamental to their overall performance, and this is variable across centers. ${ }^{28}$ Some of the reported external factors that have been thought to impede adherence are discussed below.

\section{Inadequate facilities in public toilets}

Due to difficulties with performing CISC in public toilets, patients often make it a point to self-catheterize before leaving home. ${ }^{18}$ Once outside, patients often face problems with inadequate facilities in public toilets for carrying out self-catheterization. These include inadequate shelf space or countertops for placing catheter products and accessories. Relevant to neurological patients, facilities within disabled toilets such as handrails may not be suitably built to allow patients easy transfer from a wheelchair onto the toilet. Inadequate cleanliness and washing facilities may also pose as barriers for performing clean catheterization in public toilets. ${ }^{18}$ In the UK, the national key scheme (Radar NKS Key) by "The Disability Rights People," offers access to 9,000 locked public toilets, which may be more suitable for a clean technique as they are less used by the general public. ${ }^{29}$ More recently, a smartphone app has been designed that instantly locates the nearest toilet and provides directions by road, bus, or foot. In another study it was observed that patients also found it difficult to combine social activity with CISC, as they were unsure if they would be able to locate a suitably equipped toilet in public places. ${ }^{23}$ Some older patients striving for optimum adherence opt for home based activities and turn down social events and interactions to allow them to honor their commitment to CISC adherence. Follow-up care was also found to be insufficient, and patients felt that they should not disturb health care providers with their uncertainties. ${ }^{23} \mathrm{CISC}$ also usually took more time than normal voiding, and patients felt that this was inconvenient for their daily routines.

\section{Availability of appropriate catheters and assisting appliances}

Inability to access the right type of catheter is often cited by patients as a reason for discontinuing CISC. ${ }^{18}$ Catheter size, type, and material influence the comfort of catheterization. It is crucial, therefore, that the patient selects a catheter with which they are competent and comfortable using. The use of

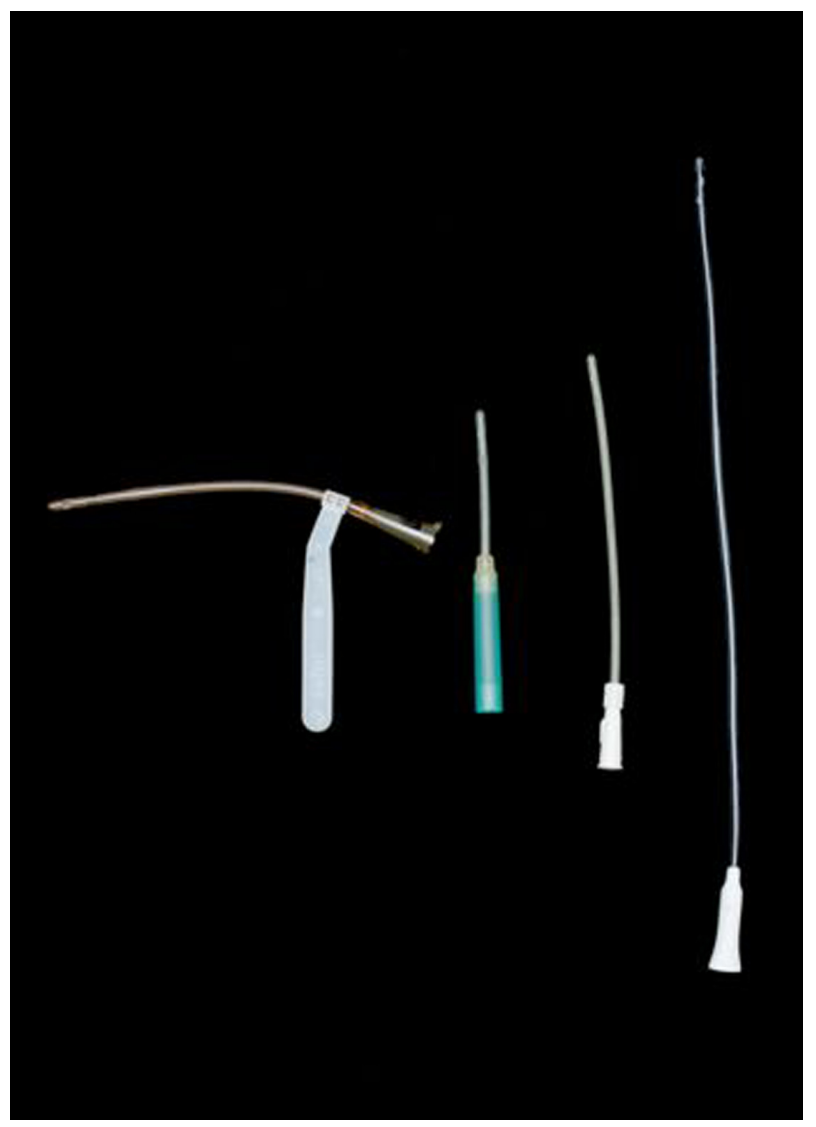

Figure I A range of single use catheters, and a catheter holder for patients having difficulties with fine finger coordination. 
hydrophilic or gel reservoir catheters may offer more comfort and ease of use. ${ }^{30,31}$

Most catheters available for CISC are single use and disposable. ${ }^{32}$ There are a number of catheters available on the market, each with its own features (Figure 1), which provide patients with the opportunity to choose according to personal preferences and ability to carry out the procedure. The nurse who teaches the procedure usually makes a recommendation about the catheter they feel would be the most suitable; therefore, knowledge of the products available on the market, as well as experience in usage, are important factors. ${ }^{33}$ Currently, there is no study that has shown a particular catheter type or technique, ie, clean or sterile, to be superior over another.

In addition, appliances are available that help to facilitate CISC, such as leg abductors and knee spreaders, catheter holders, penis holders, and aids to spread the labia (Figure 2). The use of a mirror is often required initially by women to help locate the urethra, although once proficient, this may no longer be required.

An efficient catheter delivery system is paramount so that patients have a regular supply of catheters. In the UK, catheters are available on prescription and costs are borne by the health care system. Moreover, home delivery systems are available for the regular delivery of catheters and therefore patients are generally able to access the catheter product that best suits them. In many countries, however, the cost of CISC is not fully borne by the health care system and patients may have to purchase their own supply of catheters.

\section{Quality of teaching and the training environment}

Lack of proper training was cited as a barrier to CISC in 5\% of patients in one study, ${ }^{18}$ which highlights the importance

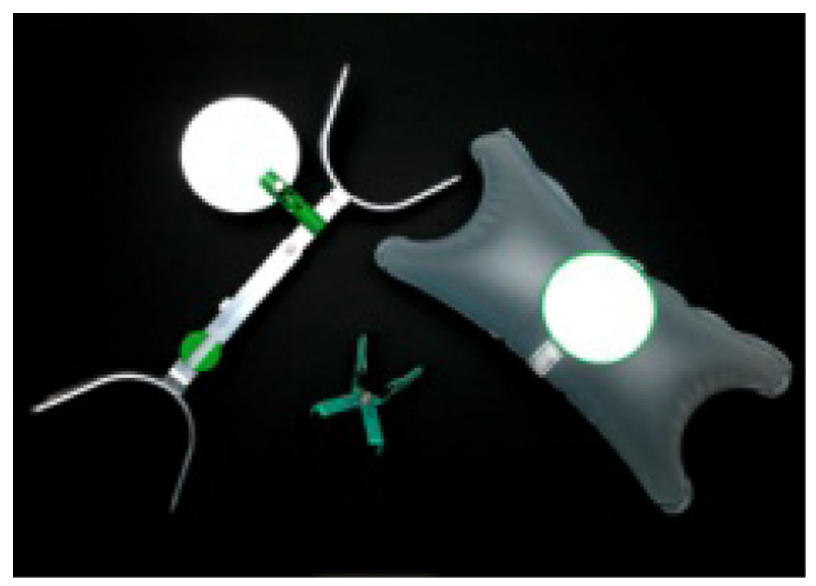

Figure 2 Appliances available to help facilitate clean intermittent self-catheterization. Note: Shown are thigh abductors, mirrors, and labial spreaders. of having a nurse experienced in teaching the technique who can spend sufficient time with the patient to go through the various types of catheters and the procedure itself.

The training environment should be quiet, private, and comfortable, with dignity and privacy maintained at all times. Some patients may require only one teaching session, whilst others may need a few sessions to feel confident with the technique. The frequency of CISC required should be advised at the time of training, and can range from once daily up to six times a day for the patient in complete urinary retention. This, however, depends upon fluid intake, as the primary aim is to prevent the bladder from overdistending and to drain any significant residual volumes which may lead to infection. ${ }^{34}$

Visual aids, such as diagrams of lower urinary tract anatomy, can be helpful whilst demonstrating the technique. Teaching videos are of great assistance for patients learning the method, however these should not replace face to face sessions with a nurse. There are also a number of leaflets in different languages produced by various catheter manufacturers that can help with disseminating information about CISC. Clinical representatives working for catheter companies may work alongside continence advisors or community workers and help support the journey of the patient. Adequate patient information appears to be paramount to successful catheterization. ${ }^{35}$ In our practice, patients are also given advice on potential complications such as UTIs and how to collect a urine specimen, and access treatment if necessary.

\section{Community follow-up and access to help or advice}

A large national cohort of patients with SCI collected over a 30 year period showed a significant drop in the number of patients continuing with CISC, which was shown to be as low as $20 \%$ after discharge into the community. ${ }^{36}$ This was considered to be due to the lack of community support and a structured pathway for troubleshooting in case of problems. Patients will need ongoing support and so it is important to provide patients and carers with a contact telephone number for them to arrange appointments, or to discuss issues and concerns. Many of these can be resolved over the telephone and may avoid unnecessary hospital visits or admissions. Once taught, patients should still be followed to ensure the proper technique is consistently being used.

\section{Involving carers}

In certain situations, the technique may also be taught to carers of the patient, if consent is agreed to. Dexterity in patients with progressive neurological conditions such as MS 
may decline with time, and the true extent of disability and its impact on the ability to perform CISC may be difficult to assess. In these circumstances, it may be important to teach a family member as well. However, if the caregiver is the patient's partner, performing CISC may affect the dynamics of the relationship, diminish sexuality, and would need to be carefully discussed.

The concept of CISC initially is often alien to the patient and for this to be successful, patients need to be motivated, with a clear understanding of the reasons for starting CISC, and the duration they will be performing this. Ongoing professional support and advice is essential for patient compliance. The initial technique may be taught within a secondary care setting, but must be followed up at the patient's home or in a community outpatient clinic.

\section{Complications of CISC}

The most frequent complication of CISC is a UTI. Learning about hygiene and aseptic techniques is embedded in the teaching of CISC and is a simple, cost effective measure for reducing UTIs. ${ }^{37}$ A recent Cochrane review suggests lack of evidence favoring the use of sterile or clean technique, coated or uncoated catheters, single or multiple use catheters, self-catheterization or catheterization by others, or any other strategy, influences the incidence of UTIs. ${ }^{38}$

Other complications, such as bleeding and pain, most often due to trauma, are barriers to successful catheterization. This should be carefully addressed by a review of technique and support from a trained nurse.

\section{Conclusion}

There are several factors that may act as barriers to successful CISC. These can range from the physical and psychological factors, to the understanding of the importance of the procedure, the reasons for performing CISC, the nature of the condition, the patient's perception of the treatment, and its implications. External factors that may influence adherence include quality of the teaching, supervision, reassurance, and follow-up, whilst internal factors include the patient's physical and psychosocial barriers and attitudes to CISC.

Misconceptions of the risks of CISC should be explored and reassurance given to patients, with a realistic idea of the side effects that can be anticipated. Patients may be overwhelmed by CISC, and spreading out the training over several visits may be beneficial. Adequate follow-up is essential, and patients should be reassured with a nonjudgmental approach. Professional support from an experienced nurse specialist may be of use in patients who find the psychological impact of incorporating CISC into their daily routine overwhelming. A dedicated professional set up which provides high quality teaching, continual advice, reassurance, and support, improves the adherence to CISC and improves the patient's quality of life.

\section{Disclosure}

JHS is funded by The Urology Foundation Research Fellowship and JNP is supported by the National Institute for Health Research University College London Hospitals Biomedical Research Centre. JNP declares receiving honoraria from Astra Tech. JHS and CH declare no conflicts of interest in this work.

\section{References}

1. Guttmann L, Frankel H. The value of intermittent catheterisation in the early management of traumatic paraplegia and tetraplegia. Paraplegia. 1966;4:63-84.

2. Lapides J, Diokno AC, Silber SJ, Lowe BS. Clean, intermittent self-catheterization in the treatment of urinary tract disease. $J$ Urol. 1972;107:458-461.

3. Webb RJ, Lawson AL, Neal DE. Clean intermittent self-catheterisation in 172 adults. Br J Urol. 1990;65:20-23.

4. Abrams P, Cardozo L, Fall M, et al; Standardisation Sub-Committee of the International Continence Society. The standardisation of terminology in lower urinary tract function: report from the standardisation sub-committee of the International Continence Society. Urology. 2003;61:37-49.

5. Fowler CJ, Panucker JN, Drake M, et al. A UK consensus on the management of the bladder in multiple sclerosis. J Neurol Neurosurg Psychiatry. 2009;80:470-477.

6. Lower urinary tract symptoms: The management of lower urinary tract symptoms in men. NICE clinical guideline (CG97) May 2010. Available from http://guidance.nice.org.uk/cg97. Accessed October 3, 2013.

7. Cruz F, Herschorn S, Aliotta P, et al. Efficacy and safety of onabotulinumtoxinA in patients with urinary incontinence due to neurogenic detrusor overactivity: a randomised, double-blind, placebocontrolled trial. Eur Urol. 2011;60:742-750.

8. Ginsberg D, Gousse A, Keppenne V, et al. Phase 3 efficacy and tolerability study of onabotulinumtoxinA for urinary incontinence from neurogenic detrusor overactivity. J Urol. 2012;187:2131-2139.

9. Sylora JA, Gonzalez R, Vaughn M, Reinberg Y. Intermittent selfcatheterization by quadriplegic patients via a catheterizable Mitrofanoff channel. J Urol. 1997;157:48-50.

10. Pilloni S, Krhut J, Mair D, Madersbacher H, Kessler TM. Intermittent catheterisation in older people: a valuable alternative to an indwelling catheter? Age Ageing. 2005;34:57-60.

11. Kessler TM, Ryu G, Burkhard FC. Clean intermittent selfcatheterization: a burden for the patient? Neurourol Urodyn. 2009;28: $18-21$.

12. Gray M, Rayome R, Anson C. Incontinence and clean intermittent catheterization following spinal cord injury. Clin Nurs Res. 1995;4:6-18.

13. Chai T, Chung AK, Belville WD, Faerber GJ. Compliance and complications of clean intermittent catheterization in the spinal cord injured patient. Paraplegia. 1995;33:161-163.

14. Girotti ME, MacCornick S, Perisse H, Batezini NS, Almeida FG. Determining the variables associated to clean intermittent selfcatheterization adherence rate: one-year follow-up study. Int Braz J Urol. 2011;37:766-772.

15. Perkash I, Giroux J. Clean intermittent catheterization in spinal cord injury patients: a followup study. $J$ Urol. 1993;149:1068-1071. 
16. Maynard FM, Glass J. Management of the neuropathic bladder by clean intermittent catheterisation: 5 year outcomes. Paraplegia. 1987;25: 106-110.

17. Shaw C, Logan K, Webber I, Broome L, Samuel S. Effect of clean intermittent self-catheterization on quality of life: a qualitative study. J Adv Nurs. 2008;61:641-650.

18. Bolinger R, Engberg S. Barriers, Complications, Adherence, and Self-reported Quality of Life for People Using Clean Intermittent Catheterization. J Wound Ostomy Continence Nurs. 2013;40:83-89.

19. Amarenco G, Guinet A, Jousse M, Verollet D, Ismael SS. Pencil and paper test: a new tool to predict the ability of neurological patients to practice clean intermittent self-catheterization. J Urol. 2011;185: $578-582$.

20. Vahter L, Zopp I, Kreegipuu M, Kool P, Talvik T, Gross-Paju K. Clean intermittent self-catheterization in persons with multiple sclerosis: the influence of cognitive dysfunction. Mult Scler. 2009;15:379-384.

21. Shaw C, Logan K. Psychological coping with intermittent self-catherisation (ISC) in people with spinal injury: A qualitative study. Int J Nurs Stud. 2013;50:1341-1350.

22. Jaquet A, Eiskjaer J, Steffensen K, Laursen BS. Coping with clean intermittent catherization - experiences from a patient perspective. Scand J Caring Sci. 2009;23:660-666.

23. van Achterberg T, Holleman G, Cobussen-Boekhorst H, Arts R, Heesakkers J. Adherence to clean intermittent self-catheterization procedures: determinants explored. J Clin Nurs. 2008;17:394-402.

24. McConville A. Patients' experiences of clean intermittent catheterisation. Nurs Times. 2002;98:55-56.

25. Borzyskowski M, Cox A, Edwards M, Owen A. Neuropathic bladder and intermittent catheterization: social and psychological impact on families. Dev Med Child Neurol. 2004;46:160-167.

26. Thomas S. Good practice in continence services. Nurs Stand. 2000;14(47):43-45.

27. DH Long-term Conditions NSF Team. The National Service Framework for Long-term Conditions. Leeds, UK. Department of Health; 2005. Available from: https:/www.gov.uk/government/uploads/system/ uploads/attachment_data/file/198114/National_Service_Framework_ for_Long_Term_Conditions.pdf. Accessed October 10, 2013.
28. Bennett E. Intermittent self-catheterisation and the female patient. Nurs Stand. 2002;17:37-42.

29. radar. The National Key Scheme, 2013. Available from http://www. radar-shop.org.uk/. Accessed October 3, 2013.

30. Martins G, Soler ZA, Batigalia F, Moore KN. Clean intermittent catheterization: educational booklet directed to caregivers of children with neurogenic bladder dysfunction. JWound Ostomy Continence Nurs. 2009;36:545-549.

31. Bermingham SL, Hodgkinson S, Wright S, Hayter E, Spinks J, Pellowe C. Intermittent self catheterisation with hydrophilic, gel reservoir, and non-coated catheters: a systematic review and cost effectiveness analysis. BMJ. 2013;346:e8639.

32. Haslam J, Gonzales G, Haslam C. General measures and nonpharmacological approaches. In: Fowler CJ, Panicker JN, Emmanuel A, editors. Pelvic Organ Dysfunction in Neurological Disease. New York: Cambridge University Press; 2010:79-89.

33. Vahr S, Cobussen-Boekhorst H, Eikenboom J, et al. Catherisation: urethral intermittent in adults. European Association of Urology Nurses. Drukkerij Gelderland Arnhem: The Netherlands; 2013.

34. Hunt GM, Oakeshott P, Whitaker RH. Intermittent catheterisation: simple, safe, and effective but underused. BMJ. 1996;312:103-107.

35. Le Breton F, Guinet A, Verollet D, Jousse M, Amarenco G. Therapeutic education and intermittent self-catheterization: recommendations for an educational program and a literature review. Ann Phys Rehabil Med. 2012;55:201-212.

36. Cameron AP, Wallner LP, Tate DG, Sarma AV, Rodriguez GM, Clemens JQ. Bladder management after spinal cord injury in the United States 1972 to 2005. J Urol. 2010;184:213-217.

37. Barber DB, Woodard FL, Rogers SJ, Able AC. The efficacy of nursing education as an intervention in the treatment of recurrent urinary tract infections in individuals with spinal cord injury. SCI Nurs. 1999;16:54-56.

38. Moore KN, Fader M, Getliffe K. Long-term bladder management by intermittent catheterisation in adults and children [review]. Cochrane Database Syst Rev. 2007;4:CD006008.
Patient Preference and Adherence

\section{Publish your work in this journal}

Patient Preference and Adherence is an international, peer-reviewed, open access journal focusing on the growing importance of patient preference and adherence throughout the therapeutic continuum. Patient satisfaction, acceptability, quality of life, compliance, persistence and their role in developing new therapeutic modalities and compounds to
Dovepress

optimize clinical outcomes for existing disease states are major areas of interest. This journal has been accepted for indexing on PubMed Central. The manuscript management system is completely online and includes a very quick and fair peer-review system. Visit http://www.dovepress.com/ testimonials.php to read real quotes from published authors. 